
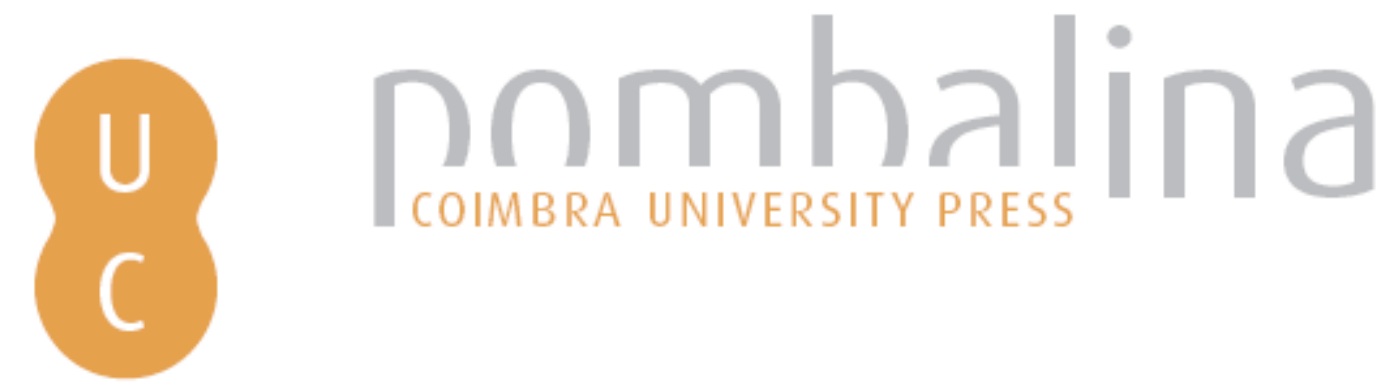

\title{
Classificação de precipitações associadas a aluviões na região do Funchal, ilha da Madeira, com recurso a cadeias de Markov
}

\begin{tabular}{ll} 
Autor(es): & Ramalheira, Ana; Portela, Maria Manuela; Almeida, António Betâmio de \\
Publicado por: & $\begin{array}{l}\text { Imprensa da Universidade de Coimbra; RISCOS - Associação } \\
\text { Portuguesa de Riscos, Prevenção e Segurança }\end{array}$ \\
$\begin{array}{ll}\text { URL } \\
\text { persistente: }\end{array}$ & URI:http://hdl.handle.net/10316.2/34802 \\
$\begin{array}{ll}\text { DOI: } & \text { DOI:http://dx.doi.org/10.14195/978-989-96253-3-4_10 } \\
\text { Accessed : } & \text { 26-Apr-2023 01:58:37 }\end{array}$ \\
\hline
\end{tabular}

A navegação consulta e descarregamento dos títulos inseridos nas Bibliotecas Digitais UC Digitalis, UC Pombalina e UC Impactum, pressupõem a aceitação plena e sem reservas dos Termos e Condições de Uso destas Bibliotecas Digitais, disponíveis em https://digitalis.uc.pt/pt-pt/termos.

Conforme exposto nos referidos Termos e Condições de Uso, o descarregamento de títulos de acesso restrito requer uma licença válida de autorização devendo o utilizador aceder ao(s) documento(s) a partir de um endereço de IP da instituição detentora da supramencionada licença.

Ao utilizador é apenas permitido o descarregamento para uso pessoal, pelo que o emprego do(s) título(s) descarregado(s) para outro fim, designadamente comercial, carece de autorização do respetivo autor ou editor da obra.

Na medida em que todas as obras da UC Digitalis se encontram protegidas pelo Código do Direito de Autor e Direitos Conexos e demais legislação aplicável, toda a cópia, parcial ou total, deste documento, nos casos em que é legalmente admitida, deverá conter ou fazer-se acompanhar por este aviso.

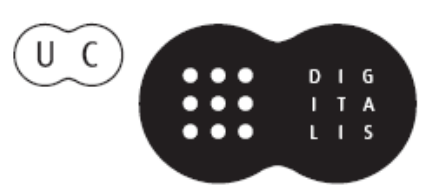



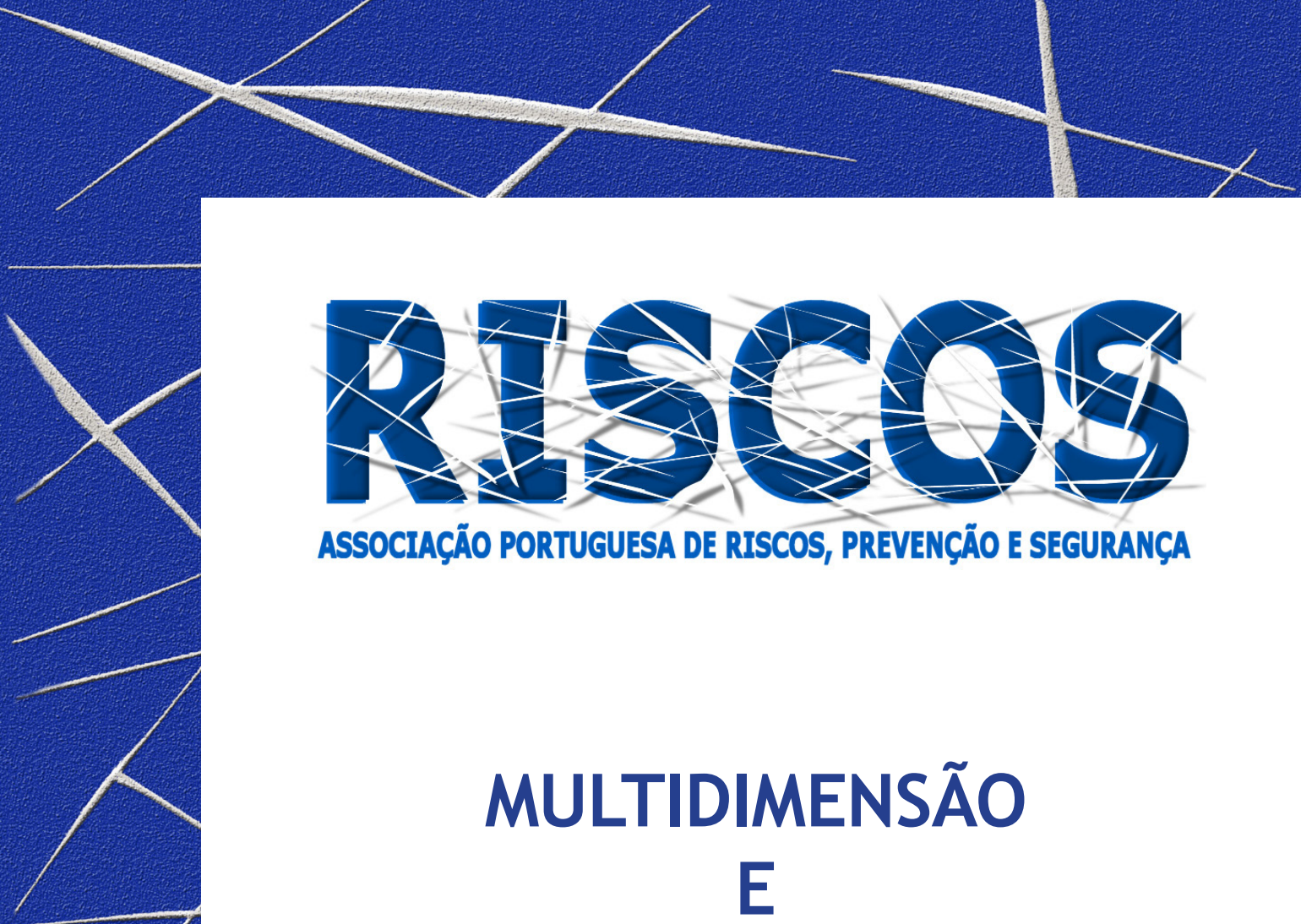

ASSOCIAÇÃO PORTUGUESA DE RISCOS, PREVENCCÃO E SEGURANÇA

MULTIDIMENSÃO

E
TERRITÓRIOS DE RISCO

III Congresso Internacional

I Simpósio Ibero-Americano

VIII Encontro Nacional de Riscos

Guimarães

2014 


\title{
CLASSIFICAÇÃO DE PRECIPITAÇÕES ASSOCIADAS A ALUVIÕES NA REGIÃO DO FUNCHAL, ILHA DA MADEIRA, COM RECURSO A CADEIAS DE MARKOV
}

\author{
Ana Ramalheira \\ Departamento de Engenharia Civil, Arquitectura e Georrecursos (DECivil), I.S.T. \\ a.c.ramalheira@gmail.com \\ Maria Manuela Portela \\ Departamento de Engenharia Civil, Arquitectura e Georrecursos (DECivil), I.S.T \\ maria.manuela.portela@ist.utl.pt \\ António Betâmio de Almeida \\ Departamento de Engenharia Civil, Arquitectura e Georrecursos (DECivil), I.S.T \\ aba@ist.utl.pt
}

\begin{abstract}
RESUMO
As ocorrências de eventos extremos de precipitação na ltha da Madeira sugerem que a excepcionalidade desses eventos, quando exclusivamente considerada per se, possa não explicar a gravidade das consequências de alguns dos mesmos. Com efeito, admite-se que precipitações intensas com magnitudes próximas possam ter consequências distintas (inclusivamente, gerando ou não aluviões), presumivelmente em função das precipitações que as antecederam. Com o objectivo de averiguar a possibilidade de estabelecer critérios de dimensionamento que reconheçam situações de risco, descreve-se a abordagem desenvolvida para classificar eventos extraordinários de precipitação a qual faz intervir precipitações superiores a limiares de excepcionalidade pré-definidos acumuladas em diferentes períodos sub-diários, ao longo de uma janela temporal à qual, nas aplicações efectuadas, se atribuiu a duração fixa de 4 dias. Para o efeito, recorreu-se à metodologia associada às cadeias de Markov, no pressuposto de as ocorrências de dias secos ou chuvosos serem condicionalmente dependentes da sequência antecedente daqueles dias. A abordagem foi aplicada à classificação de precipitações associadas a aluviões históricas na região do Funchal.

Palavras-chave: aluvião, cadeias de Markov, Funchal, precipitações excepcionais.
\end{abstract}

\section{Introdução}

As precipitações de Fevereiro de 2010 na região do Funchal, de que resultaram 47 mortes e elevados prejuízos materiais, sugerem que, para entender as consequências de alguns dos acontecimentos pluviosos intensos na Ilha da Madeira, possa ser necessário avaliar, para além das precipitações verificadas nas datas das suas ocorrências, as condições antecedentes de precipitação, designadamente no que respeita a precipitações acumuladas em dias anteriores a esses eventos.

Para equacionar a anterior expectativa ensaiou-se uma classificação dos acontecimentos pluviosos associados à ocorrência de aluviões na região do Funchal, de entre as identificadas por Quintal, 1999, e Abreu, 2013. Para o efeito utilizou-se a série de precipitações horárias no posto udográfico do Funchal, no período entre as 09:00 h de 1 de Outubro de 1980 e as 18:00 h de 06 de Julho de 2010, obtida no âmbito de SRES, 2010. Importa mencionar que os registos apresentavam falhas muito pontuais e em períodos habitualmente de baixo quantitativo de precipitação, que foram preenchidas atendendo aos registos diários nos períodos com falhas horárias. A classificação incidiu sobre precipitações acumuladas com diferentes durações sub diárias, embora perfazendo sempre o período total de acumulação da precipitação de 4 dias. As datas com registo de ocorrência de aluviões na zona do Funchal e para as quais se precedeu à classificação de precipitações acumuladas foram as seguintes: 01.03.1984, 02.03.1984, 
27.09.1989, 18.09.1990, 24.10.1991, 29.10.1991, 29.10.1993, 19.10.1997, 20.10.1997, 01.02.1998, 05.03.2001, 06.03.2001, 18.11.2007, 19.11.2007, 29.11.2007, 07.04.2008, 08.04.2008, 09.04.2008 e 22.12.2009. Dada a excepcionalidade da aluvião registada dias 20 e 21 de Fevereiro de 2010, e uma vez que se dispõe dos dados referentes a esse período, tais datas foram incluídas no conjunto das analisadas (num total de 21 datas).

Dado que a informação de que se dispõe sobre as aluviões históricas apenas especifica dias de ocorrência, houve que estabelecer o critério de cálculo de precipitações acumuladas antecedendo essas aluviões. Para o efeito, atendendo a que cada registo horário de precipitação é atribuído à hora que se segue à sua ocorrência, admitiu-se que as $24 \mathrm{~h}$ relativas a uma dada aluvião poderiam decorrer entre a 01:00 e as 24:00 h do dia especificado para a aluvião, ou seja, entre a 01:00 h desse dia e as 0:00 h do dia seguinte, como se exemplifica na Figura 1 para a aluvião histórica de dia 29.10.1993. Cada uma dessas $24 \mathrm{~h}$ foi designada por data de referência, tendo-se especificado para a mesma as precipitações acumuladas em diferentes períodos subdiários nos 4 dias $(96 \mathrm{~h}$ ) antecedentes, finalizando nessa data, como se esquematiza mais adiante, na Figura 2. A data de referência foi, portanto, considerada móvel ao longo da janela de $24 \mathrm{~h}$ antes especificada (entre 01:00 h do dia da aluvião e as 0:00 h do dia seguinte).

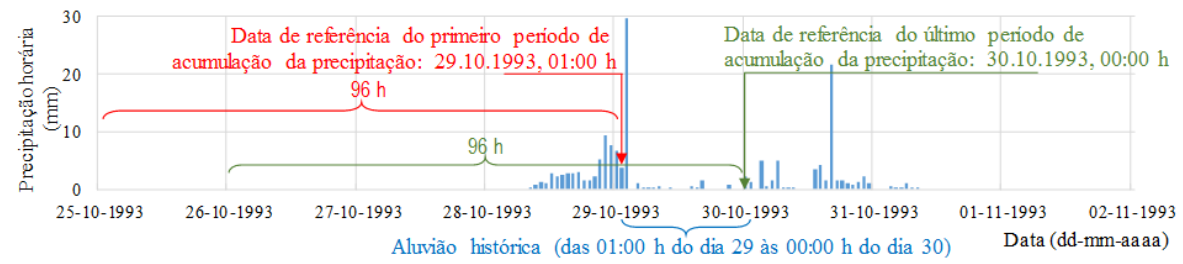

Figura 1 - Representação gráfica das datas de referência extremas associadas à aluvião histórica de dia 29.10.1993 (registos de precipitações horárias entre 25.10.1993, 00:00 h, e 03.11.1993, 00:00 h).

\section{Cadeias de Markov}

A utilização de matrizes de frequência de cadeias de Markov baseia-se na hipótese de as ocorrências de dias secos ou chuvosos serem condicionalmente dependentes da sequência dos dias secos ou chuvosos antecedentes (Andrade et al., 2009). Na aplicação de tais cadeias à classificação das precipitações associadas a uma dada aluvião na zona do Funchal especificouse, para cada uma das correspondentes 24 datas de referência, a precipitação acumulada nas $96 \mathrm{~h}$ finalizando nessa data, para o que as $96 \mathrm{~h}$ foram descritas por sucessivos sub períodos com duração de $k$ de $1,3,4,6,8,12$ e 24 h. Deste modo, o número de estados a classificar, $n$, correspondentes aos anteriores valores de $k$ é de $96,32,24,16,12,8$ e 4, respectivamente. Esses estados foram classificados através de cadeias de zeros (estados não excepcionais) e de uns (estados excepcionais). A precipitação acumulada num qualquer intervalo de $d \mathrm{~h}$ foi considerada excepcional quando superior ao quantil empírico para a probabilidade de não-excedência de 75\%, $\mathrm{P}_{\bar{Z}}^{\mathrm{d}} \%$, obtido por mera ordenação das precipitações máximas anuais com a duração de $d$ h no período de 29 anos hidrológicos (de 1980/81 a 2008/09) em que por acumulação de precipitações horárias foi possível constituir as amostras de máximos anuais. O Quadro I exemplifica algumas das precipitações excepcionais assim obtidas e o Quadro II, a 
utilização das cadeias de Markov. Nas cadeias de três dígitos o dígito mais à esquerda classifica a precipitação no intervalo de tempo de $k h$ que finaliza na data de referência (intervalo de tempo mais recente).

Quadro I - Posto udográfico do Funchal. Precipitações excepcionais, ${ }^{\mathrm{d}} \%(\mathrm{~mm})$.

\begin{tabular}{|c|c|c|c|c|c|c|c|c|c|}
\cline { 2 - 10 } \multicolumn{1}{c|}{} & $d=1 \mathrm{~h}$ & $d=2 \mathrm{~h}$ & $d=3 \mathrm{~h}$ & $d=4 \mathrm{~h}$ & $\ldots$. & $d=93 \mathrm{~h}$ & $d=94 \mathrm{~h}$ & $d=95 \mathrm{~h}$ & $d=96 \mathrm{~h}$ \\
\hline $75 \%$ & 28.7 & 40.8 & 47.1 & 53.2 & $\ldots$ & 124.6 & 126.8 & 126.9 & 131.5 \\
\hline
\end{tabular}

Quadro II - Exemplo de obtenção das cadeias de Markov de segunda ordem.

\begin{tabular}{|c|c|c|c|}
\hline \multirow{2}{*}{$\begin{array}{c}\mathrm{x}_{2} \text { (estado da precipitação } \\
\text { acumulada com (t-1) e (t-2) } \\
\text { (duração total de } 3 \mathrm{k} \mathrm{h})\end{array}$} & \multirow{2}{*}{$\begin{array}{l}\mathrm{x}_{1} \text { (estado da precipitação } \\
\text { acumulada com (t-1) } \\
\text { (duração total de } 2 \mathrm{k} \text { h) }\end{array}$} & \multicolumn{2}{|c|}{$\mathrm{x}_{0}$ (estado da precipitação em $\mathrm{t}$ (duração total de $\mathrm{k} \mathrm{h}$ ) } \\
\hline & & $\mathrm{x}_{0} \leq \mathrm{P}_{75 \%}^{1 \mathrm{k}} \Rightarrow 0$ & $\mathrm{x}_{0}>\mathrm{P}_{75 \%}^{\mathrm{lk}} \Rightarrow 1$ \\
\hline \multicolumn{2}{|c|}{$\mathrm{x}_{2} \leq \mathrm{P}_{75 \%}^{3 \mathrm{k}} \wedge \mathrm{x}_{1} \leq \mathrm{P}_{75 \%}^{2 \mathrm{k}} \Rightarrow 00$} & 000 & 001 \\
\hline \multicolumn{2}{|c|}{$\mathrm{x}_{2} \leq \mathrm{P}_{75 \%}^{3 \mathrm{k}} \wedge \mathrm{x}_{1}>\mathrm{P}_{75 \%}^{2 \mathrm{k}} \Rightarrow 01$} & 010 & 011 \\
\hline \multicolumn{2}{|c|}{$\mathrm{x}_{2}>\mathrm{P}_{75 \%}^{3 \mathrm{k}} \wedge \mathrm{x}_{1} \leq \mathrm{P}_{75 \%}^{2 \mathrm{k}} \Rightarrow 10$} & 100 & 101 \\
\hline \multicolumn{2}{|c|}{$\mathrm{x}_{2}>\mathrm{P}_{75 \%}^{3 \mathrm{k}} \wedge \mathrm{x}_{1}>\mathrm{P}_{75 \%}^{2 \mathrm{k}} \Rightarrow 11$} & 110 & 111 \\
\hline
\end{tabular}

De forma generalizada ter-se-á:

$$
X_{n}=\left\{\begin{array}{l}
0, \text { se } x_{n} \leq P_{75 \%}^{(n+1) k} \\
1, \text { se } x_{n}>P_{75 \%}^{(n+1) k}
\end{array}\right.
$$

em que $n$ representa o número de estados a classificar, $X_{n}$, o estado da precipitação acumulada nos instantes $t a t-k$ (ou seja, em $n k$ horas ) e $x_{n}$, o valor dessa precipitação. A Figura 2 exemplifica para as aluviões históricas de 08.04.2008 e de 20.02.2010 o procedimento de constituição de uma das 24 sequências de precipitações acumuladas, para os valores de $k$ de 1, 6 e 24 (números de estados, $n$, de 96, 16 e 4, respectivamente, conforme representado na figura). Para essas mesmas duas aluviões, especifica-se no Quadro III a composição das cadeias de Markov para $k=1$. 

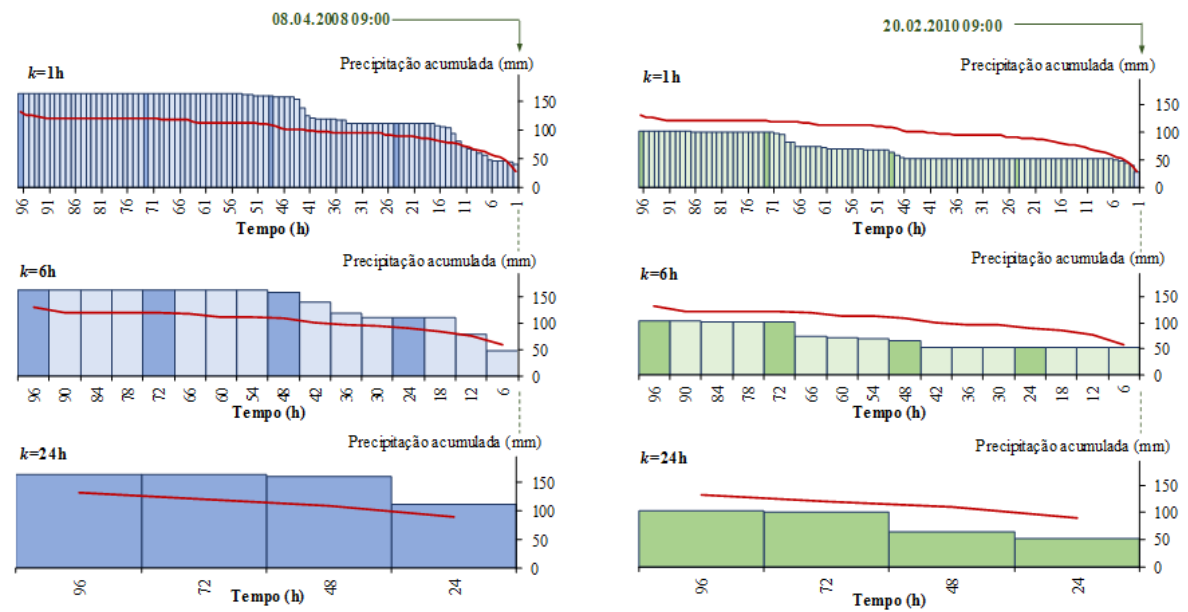

Figura 2 - Precipitações acumuladas nas 96 h, para $k$ igual a 1,6 e 24, para as datas de referência de 08.04.2008, às 09:00, e 20.02.2010, às 09:00 (a curva vermelha de cada gráfico representa o limiar de excepcionalidade, $\mathrm{P}_{\tilde{b} \%}^{\mathrm{d}}$, para durações $d$ até $96 \mathrm{~h}$, discretizadas de $k$ em $k \mathrm{~h}$ ).

\section{Quadro III - Precipitações acumuladas nas datas de referência associadas às aluviões} históricas de 08.04.2008 e 20.02.2010 e corresponden tes cadeias de Markov para $k=1$.

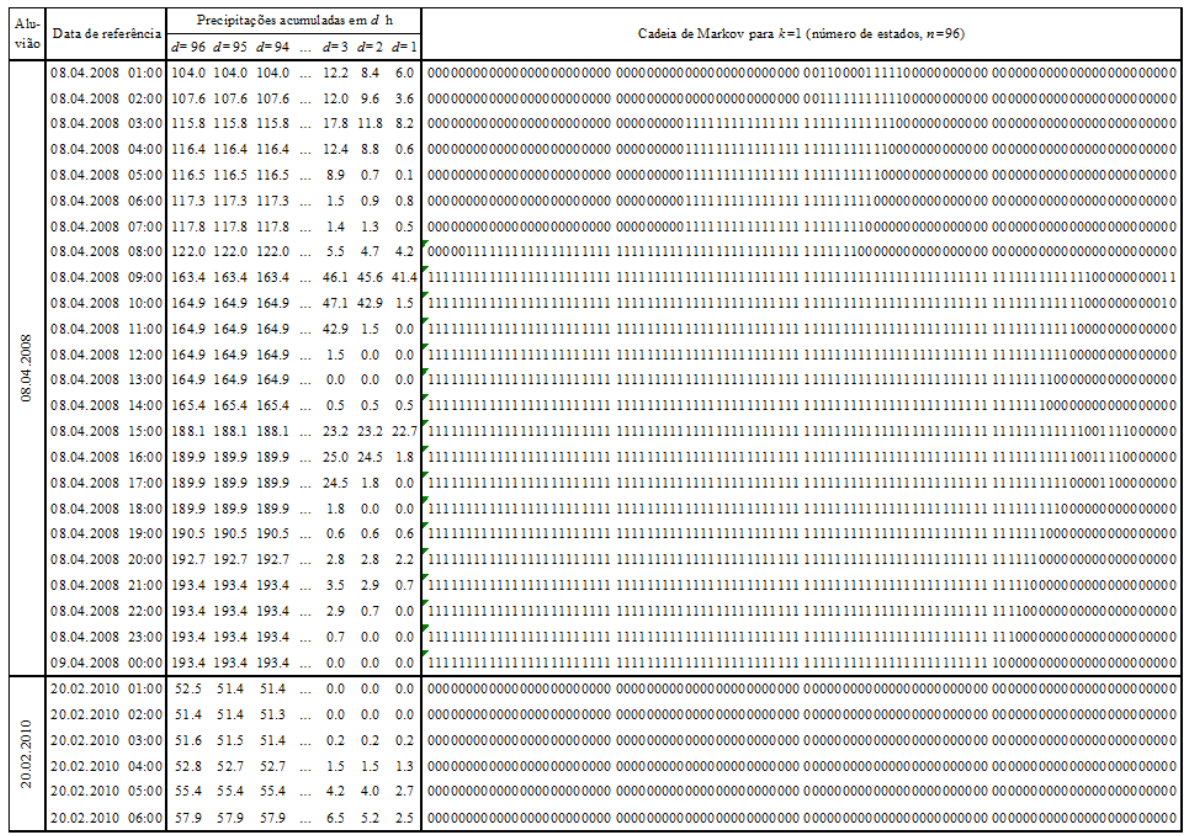


Quadro III (continuação).

\begin{tabular}{|c|c|c|c|c|c|c|c|c|}
\hline \multirow{2}{*}{$\begin{array}{l}\text { Alv- } \\
\text { vião }\end{array}$} & \multirow{2}{*}{ Data de referência } & \multicolumn{6}{|c|}{ Precipitações acumuladas em $d \mathrm{~h}$} & \multirow{2}{*}{ Cadeia de Markov para $k=1$ (número de estados, $n=96$ ) } \\
\hline & & $d=96$ & $d=95$ & $d=94 \ldots$ & $d=3$ & $d=2$ & $d=1$ & \\
\hline \multirow{11}{*}{ 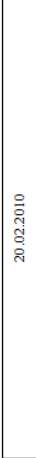 } & $20.02 .2010 \quad 08: 00$ & 74.0 & 74.0 & $74.0 \ldots$ & 18.6 & 16.1 & 10.8 & 000000000000000000000000000000000000000000000000000000000000000000000000000000000000000000000 \\
\hline & $20.02 .2010 \quad 10: 00$ & 154.2 & 153.9 & 9 $153.4 \ldots$ & 91.0 & 80.2 & 51.2 & 11111111111111111111111111111111111111111111011111111111111111111111111111111111111111111111 \\
\hline & $20.02 .2010 \quad 11: 00$ & 165.0 & 164.5 & 5164.5 & 91.3 & 62.3 & 11.1 & 111111111111111111111111111111111111111111111111111111111111111111111111111111111111111111110 \\
\hline & $20.02 .2010 \quad 12: 00$ & 173.8 & 173.8 & $3173.8 \ldots$ & 71.6 & 20.4 & 9.3 & [111111111111111111111111111111111111111111111111111111111111111111111111111111111111111111111111111100 \\
\hline & $20.02 .2010 \quad 14: 00$ & 177.3 & 177.3 & $3177.3 \ldots$ & 12.8 & 3.5 & 1.3 & [111111111111111111111111 1111111111111111111111111111111111111111111111111111111111111111110000 \\
\hline & $20.02 .2010 \quad 15: 00$ & 180.2 & 180.2 & $2179.9 \ldots$ & 6.4 & 4.2 & 2.9 & 111111111111111111111111111111111111111111111111111111111111111111111111111111111111111100000 \\
\hline & $20.02 .2010 \quad 16: 00$ & 191.7 & 191.4 & $4191.2 \ldots$ & 15.7 & 14.4 & 11.5 & 111111111111111111111111111111111111111111111111111111111111111111111111111111111111111111000000 \\
\hline & $20.02 .2010 \quad 17: 00$ & 194.9 & 194.7 & $193.5 \ldots$ & 17.9 & 15.0 & 3.5 & 1111111111111111111111111111111111111111111111111111111111111111111111111111111111111110000000 \\
\hline & $20.02 .201018: 00$ & 196.5 & 195.3 & $3195.3 \ldots$ & 16.8 & 5.3 & 1.8 & (1111111111111111111111111 111111111111111111111111111111111111111111111111111111111111111100000000 \\
\hline & $20.02 .2010 \quad 19: 00$ & 195.5 & 195.5 & $195.5 \ldots$ & 5.5 & 2.0 & 0.2 & 111111111111111111111111111111111111111111111111111111111111111111111111111111111111111000000000 \\
\hline & $21.02 .2010 \quad 00: 00$ & 195,6 & 195.6 & $5195.6 \ldots$ & 0.1 & 0.1 & 0.1 & 1111111111111111111111111111111111111111111111111111111111111111111111111111111100000000000000 \\
\hline
\end{tabular}

\section{Resultados: codificação run-length (run length encoding)}

A partir das cadeias de Markov obtidas para cada aluvião, seleccionaram-se, de entre as 24 datas de referência dessa aluvião, as com as maiores sequências de valores 1 (ou seja, as com maiores sequência de estados excepcionais) para os diferentes valores de $k$.

Verificou-se, assim, que a maior parte das aluviões referenciadas para a zona do Funchal, concretamente, doze aluviões históricas, não coincidiu com precipitações excepcionais em qualquer dos períodos de acumulação até $96 \mathrm{~h}$ e em todas das datas de referência a elas associadas (cadeias de Markov totalmente compostas por zeros). Para as restantes nove aluviões, exemplifica-se, no Quadro IV, as datas de referência conducentes às mais longas sequências de estados excepcionais consecutivos, bem como a constituição das respectivas cadeias de Markov. Para tanto, considerou-se a precipitação acumulada com discretização temporal de $1 \mathrm{~h}$, ou seja, $k=1$, por, de algum modo, tal valor de $k$ conter a informação que advém para os restantes intervalos de tempo adoptados na discretização temporal da precipitação acumulada.

\section{Quadro IV - Datas de referência seleccionadas em função da dimensão da sequência de estados excepcionais consecutivos, para $\mathrm{k}=1 \mathrm{~h}$, e cadeias de Markov geradas.}

\begin{tabular}{|c|c|c|c|}
\hline \multirow[b]{2}{*}{$\begin{array}{l}\text { Data de } \\
\text { registo da } \\
\text { aluvião } \\
\text { histórica. }\end{array}$} & \multicolumn{3}{|r|}{ Sequência/cadeia de Markov com maior número de estados excepcionais } \\
\hline & $\begin{array}{l}\text { Data de } \\
\text { referência }\end{array}$ & $\begin{array}{c}\text { Número de } \\
\text { estados } \\
\text { excepcionais } \\
\text { consecutivos }\end{array}$ & Constituição \\
\hline 27.09 .1989 & 27.09 .198906 .00 & 31 & 000000000000000000000000000000000000000000000000000000000000111111111111111111111111111111100000 \\
\hline 18.09 .1990 & $18.09 .1990 \quad 14.00$ & 1 & 000000000000000000000000000000000000000000000000000000000000000000000000000000000000000000000001 \\
\hline 29.10 .1991 & 29.10 .199111 .00 & 1 & 000000000000000000000000000000000000000000000000000000000000000000000000000000000000000000000010 \\
\hline 29.10 .1993 & 29.10 .199303 .00 & 7 & 000000000000000000000000000000000000000000000000000000000000000000000000000001111111000011110001 \\
\hline 01.02 .1998 & $01.02 .199804: 00$ & 2 & 000000000000000000000000000000000000000000000000000000000000000000000000000000000000000000000110 \\
\hline 08.04 .2008 & 08.04 .200809 .00 & 85 & 111111111111111111111111111111111111111111111111111111111111111111111111111111111111100000000011 \\
\hline 09.04 .2008 & 09.04 .200801 .00 & 72 & 111111111111111111111111111111111111111111111111111111111111111111111111000000000000000000000000 \\
\hline 20.02 .2010 & 20.02 .201011 .00 & 95 & 111111111111111111111111111111111111111111111111111111111111111111111111111111111111111111111110 \\
\hline 21.02 .2010 & 21.02 .201001 .00 & 81 & 111111111111111111111111111111111111111111111111111111111111111111111111111111111000000000000000 \\
\hline
\end{tabular}




\section{Conclusões}

O Quadro IV evidencia que as aluviões de 18.09.1990, 29.10.1991 e 01.02.1998 só apresentam excepcionalidade de precipitação acumulada em curtos períodos de tempo próximos dos dias da sua ocorrência, os quais foram precedidos por períodos de vários dias sem precipitação excepcional. Das restantes aluviões, as de Abril de 2008 e Fevereiro de 2010 foram nitidamente precedidas de precipitações consistentemente excepcionais que, contudo, ao aproximarem-se da data de referência poderão ter perdido alguma da sua excepcionalidade. Embora com manutenção de condições gravosos por um menor intervalo de tempo, é também esta a situação da aluvião de Outubro de 1989. A aluvião de Outubro de 1993 regista períodos com precipitações acumuladas acima do limiar de excepcionalidade com outros abaixo desses limiares.

A principal conclusão do estudo sumariamente apresentado prende-se com a constatação de que não é possível associar à generalidade das aluviões registdas na região do Funchal precipitações excepcionais, seja quer pelas precipitações que geraram aquelas aluviões não serem de facto excepcionais, quer por os registos referentes ao posto udográfico do Funchal não descreverem as precipitações que localmente poderão ter desencadeado essas aluviões. No extremo oposto, foram reconhecidas aluviões em períodos com pluviosidade consistentemente muito excepcional. Deve, contudo, mencionar-se que um estudo paralelo indicou outros períodos com precipitações igualmente excepcionais mas que, aparentemente, não terão ocasionado aluviões. Globalmente conclui-se que, para eficazmente associar precipitações a fenómenos de aluvião, será necessário por um lado, catalogar todas as ocorrências dessas aluviões e, por outro lado, dispor de uma rede de monitorização da precipitação sub diária que permita detalhar a variabilidade espacial desse hidrometeoro.

\section{Bibliografia}

Abreu, T. (2013). Riscos Naturais na Região Autónoma da Madeira. Análise dos Riscos Naturais de Maior Incidência. Lisboa: Faculdade de Ciências Sociais e Humanas.

Andrade, A., Freitas, J., Brito, J., Guerra, H., \& Xavier, J. (2009). Aplicação da Probabilidade Condicional e do Processo de Cadeia de Markov na Análise da Ocorrência de Periodos Secos e Chuvosos para o Municipio de Garanhuns, Pernanbuco, Brasil. Revista Ambiente e Água - An Interdisciplinary Journal of Applied Science, v4 n.1. doi:10.4136/ambi-agua.81

Quintal, R. (1999). Aluviões da Madeira. Séculos XIX e XX. Territorium 6, p. 31-48.

SRES, Secretaria Regional do Equipamento Social da Região Autónoma da Madeira (2010). Estudo de Avaliação do Risco de Aluviões da Ilha da Madeira - Estudo de avaliação do risco de aluviões na llha da Madeira. Anexo A - Caracterização de precipitações intensas. Instituto Superior Técnico (IST), Universidade da Madeira (UM), Laboratório Regional de Engenharia Civil (LREC). 